\title{
Addressing Transition to Practice: Assessing Perceived Effectiveness of a Competency Based Change to On-Call Responsibilities of Senior Cardiology Residents
}

Andrew James Caddell

Dalhousie University

Edwin Moses Bamwoya

Dalhousie University

Andrew Donald Moeller ( $\square$ Andrew.Moeller@nshealth.ca )

Dalhousie University

\section{Research Article}

Keywords: Competency by design, residency training, education, cardiology

Posted Date: October 26th, 2021

DOl: https://doi.org/10.21203/rs.3.rs-984152/v1

License: (c) (i) This work is licensed under a Creative Commons Attribution 4.0 International License.

Read Full License 


\section{Abstract \\ Background}

There has been a paradigm shift in residency training over the last several years wherein Competency by Design (CBD) is being integrated to replace more traditional time-based models of training. The Residency Program Committee (RPC) for the Cardiology training program at Dalhousie University in Halifax, Canada addressed the Transition to Practice stage by approving a trial of adjusting the resident call responsibilities to reflect the transition to CBD curriculum. The goal of this adjustment was three-fold: i. Gradually increase accountability of the senior cardiology resident as they transition to practice; ii. Address a gap in training that allows the senior resident to have a gradual transition to the role of a practicing cardiologist while on call; iii. Allows further evolution of skills and abilities.

\section{Methods}

A survey was administered to the practitioners involved in this competency-based change to the call responsibilities. Surveys were distributed to the final year Cardiology Residents, Staff Cardiologists, and Senior Internal Medicine residents to assess their experience and opinions of the current, competencybased change of the on-call curriculum. The survey consisted of eleven questions, of which, four were assessed on a Likert scale and 3 were yes/no questions.

\section{Results}

Four PGY6 cardiology residents, five senior internal medicine residents and eleven staff cardiologists completed the survey. Amongst those who completed the survey there was agreement that the change to the on-call responsibilities improved cardiology residents' skills, accountability and preparedness to practice. All groups felt the changes were useful for the cardiology training program. There was mild negative effect of perceived accountability by the internal medicine residents.

\section{Conclusion}

Overall the change in call structure led to improved perceived preparedness to practice amongst the cardiology residents and addressed a gap in the Transition to Practice phase of CBD training. This study provides some evidence to the potential benefit of $\mathrm{CBD}$ and specifically in the benefits towards transitioning to practice.

\section{Background}

There has been a paradigm shift in residency training over the last several years. All specialty programs that eventually lead to licensure with the Royal College of Physicians and Surgeons of Canada are in the 
process of changing their training framework to 'Competency by Design' (CBD). Traditionally, roles and expectations within residency programs were longitudinal and time-based. CBD breaks residency training into progressively more complex tasks called competencies (Frank, J.R. et al, 2010). As earlier tasks are successfully achieved, more complex tasks are progressively expected. These tasks are observed, evaluated and collated. When sufficient tasks are successfully performed the resident is deemed competent at that task (Frank, J.R. et al, 2010). CBD also defines milestones when sufficient tasks are completed: Transition to Discipline, Foundations, Core and Transition to Practice. Transition to Practice will occupy the last six months of cardiology training and it is expected that the resident physician is at or near the level of the specialist physician. All residency training programs in Canada are in CBD or are in the process of changing to CBD. The goal of this training mechanism is to produce well rounded specialists, and to identify any knowledge or skill gaps early in training (Frank, J.R. et al, 2010). It represents a significant departure from traditional time-based training models.

The Royal College of Physicians and Surgeons of Canada have requested all Canadian-based Cardiology Programs transition to CBD-based curriculum on July 1st, 2021. The Adult Cardiology Residency Program at Dalhousie University transitioned to a CBD-based curriculum in July of 2020. Prior to this change, and given the Royal College of Canada recommendations to gradually transition to CBD, the Residency Program Committee (RPC) for the Cardiology training program at Dalhousie University in Halifax addressed the Transition to Practice milestones by adjusting the resident call responsibilities to reflect the transition to CBD curriculum. The goal of this adjustment to call responsibilities was three-fold in order to:

1. Gradually increase accountability of the senior cardiology resident as they transition to practice;

2. Address a gap in training that allows the senior resident to have a gradual transition to the role of a practicing cardiologist while on call;

3. Allow further evolution of skills and abilities.

As there is limited evidence and research in the field of CBD, especially in Cardiology, we administered a survey to the practitioners involved in this competency-based change to the call responsibilities.

\section{Methods}

The Dalhousie Adult Cardiology Residency Program is a three-year training program that is currently based on a traditional outcomes-based and timed-based model of training. There are 8-10 residents in the program, with 2-4 residents per year of training, all of whom have successfully completed 3 years of general internal medicine training. The vast majority of trainees have completed their Internal Medicine Royal College of Canada Exams and are qualified specialists in Internal Medicine.

The Dalhousie Cardiology call schedule structure is designed to respond to site-specific requirements. The Senior Cardiology Resident is responsible for providing consultation services in the emergency department and admitted inpatients in the 200-bed hospital. They also supervise care for cardiology inpatients including a 38-bed ward, 14-bed intermediate care unit (IMCU), and a 10-bed coronary care unit (CCU). There are two junior residents, typically in their first or second year of training, to assist the Senior 
Cardiology Resident with the large amount of responsibility. There is a Staff Cardiologist on-call, who reviews consults and other issues with the Senior Cardiology Resident when applicable. If a patient is sent home from the emergency department, the Staff Cardiologist assumes responsibility of this patient. The Staff Cardiologist also triages phone calls from the entire province that may result in patient transfer, activating the cardiac catheterization lab, or advice provided over the phone.

In order to prepare Senior Cardiology Residents for Transition to Practice within CBD, the RPC allowed Senior Cardiology Residents in their final six months of training to act as the "Junior Attending" physician. This involves reviewing local consults over the phone with a senior Internal Medicine or Critical Care resident. This also includes accepting phone calls from the entire province and arranging appropriate inpatient or outpatient follow-up, as would typically be done by the Staff Cardiologist. Staff Cardiologist will be available by phone at any time for guidance. Orientation was provided to final year Cardiology Residents by way of practice scenarios. Feedback was provided the following day by the Staff Cardiologist for their decisions and in real time for complex cases.

Surveys were distributed to the final year Cardiology Residents, Staff Cardiologists, and Senior Internal Medicine residents to assess their experience and opinions of the current, competency-based change of the on-call curriculum. The survey consisted of eleven questions, of which four were assessed on a Likert scale and three were yes/no questions (Appendix 1).

The Tri-Council Policy Statement (TCPS2) governing research ethics in Canada suggests that while research must undergo ethical review, program evaluation and qualitative improvements studies do not fall under the auspices of the TCPS or institutional Research Ethics Boards (TCPS2, Article 2.5). This project was described as quality improvement and therefore a formal research ethics board approval was not recommended.

\section{Results}

There were 22 total responses. Four final year Cardiology Residents, five Senior Internal Medicine residents and eleven Staff Cardiologists completed the survey. All surveyed participants agreed that it was a useful experience having Senior Cardiology Residents to performing the role of Acting Triage Cardiologist. In addition, nearly all surveyed (21/22) agreed that changing the curriculum to include the "Junior Attending" role would be worthwhile.

Results of the survey are seen in Table 1. Amongst those who completed the survey there was agreement that the change to the on-call responsibilities improved preparedness to practice independently, and improved the Cardiology Resident's skills and accountability. Cardiology Residents and Staff Cardiologists felt the change improved skill levels. Most felt that there was no change in patient care. There was mild negative effect of perceived accountability by the Internal Medicine residents. Almost all trainees felt supported by the Staff Cardiologists. 
Table 1

Cardiology residents, internal medicine residents and staff cardiologist's response to questionnaire. Questions were responded on a 1-5 Likert scale, where 1 represents strongly worsened/ strongly negative impacted and 5 represented strongly improved/ strongly positively impacted. P-values are compared to cardiology residents.

\begin{tabular}{|llll|}
\hline & $\begin{array}{l}\text { Cardiology } \\
\text { Residents }\end{array}$ & $\begin{array}{l}\text { Internal Medicine } \\
\text { Residents }\end{array}$ & $\begin{array}{l}\text { Staff } \\
\text { Cardiologist }\end{array}$ \\
\hline $\begin{array}{l}\text { Was there a perceived improvement in } \\
\text { accountability? }\end{array}$ & $4.3 \pm 0.5$ & $2.6 \pm 0.6$ & $4.3 \pm 0.5$ \\
& & $(P=0.003)$ & $(P=1.0)$ \\
\hline $\begin{array}{l}\text { Impact of on evolution of skills and } \\
\text { abilities? }\end{array}$ & $4.3 \pm 1$ & $3.4 \pm 0.5$ & $4.4 \pm 0.5$ \\
\hline $\begin{array}{l}\text { Impact on preparation for independent } \\
\text { practice? }\end{array}$ & $5 \pm 0.1$ & $(P=0.1)$ & $(P=0.8)$ \\
\hline $\begin{array}{l}\text { Effect on patient care? } \\
\end{array}$ & $5 \pm 0.1$ & $4.8 \pm 0.4$ & $4.4 \pm 0.5$ \\
& & $(P=0.4)$ & $(P=0.6)$ \\
\hline
\end{tabular}

Figure 1 shows the domains of CanMeds that the Acting Triage Cardiologist role enhanced. Most Cardiology Residents felt that this experience enhanced their communicator (100\%), leader (100\%), collaborator $(100 \%)$ and professional domains $(75 \%)$. Staff Cardiologists felt that this experience enhanced the communicator (64\%), leader (64\%) and collaborator roles $(64 \%)$.

Unscripted free text responses were supportive of adjusting the resident call responsibilities. Cardiology Residents were unanimous in their support and asked for more potential opportunities. Comments from Internal Medicine Residents noted more thorough review of their cases, balanced against a perceived reduction in autonomy. Staff Cardiologists comments were extremely positive, with most praising the change to call as 'fantastic' and providing senior residents with 'real life experience'.

\section{Discussion}

There is limited Canadian or International data about CBD, particularly with respect to Cardiology residencies. This survey provides insight into changes made to the Dalhousie Adult Cardiology training program to align itself with the coming change to CBD and specifically the need to address Transition to Practice. By changing the call structure to a "Junior Attending" model, final year Cardiology Residents and Staff Cardiologists reported improvement in preparedness to practice, and improvement to the Cardiology Resident's skills and accountability. This increase in responsibility and workload was well tolerated and universally supported. There was mild negative effect of perceived accountability by the internal medicine residents.

Previous studies have surveyed program directors on key Transition to Practice components. A recent Canadian study listed: "further sophistication of clinical skills", "time management skills", "experience in 
a high-volume environment" and "leadership" as the four most commonly identified skills to develop during Transition to Practice (Sanaee et al, 2020). Residents from Queen's University have listed better preparation for independent clinical practice as a potential benefit of CBD (Mann et al, 2020).

Within Canada, residency programs have developed varying solutions for Transition to Practice. Ottawa Urology developed a resident-run clinic with excellent clinical results and provider satisfaction

(Witherspoon et al, 2019). Radiation oncology training program focus groups have identified a number of potential options including simulation, resident clinics and formal education materials (Best et al, 2019). To our knowledge there has not been literature on Adult Cardiology training programs.

Potential advantages to changing the call structure to a "Junior Attending" model include increasing accountability and transparency in training. It also better prepares residents for independent practice. Additionally, the Staff Cardiologist is able to give effective real time feedback and complete assessments required of the Transition to Practice stage.

\section{Conclusion}

In the current era of accountability, society and governing bodies demand that our system consistently produces competent practitioners. Allowing final year cardiology residents to act as the "Junior Attending", with structured back-up and opportunities for feedback, led to improved perceived preparedness to practice amongst the cardiology residents and was felt to be a useful change from the previous call structure. This study provides some evidence to the potential benefit of CBD and specifically in the benefits towards transitioning to practice.

\section{Abbreviations}

Competency by Design (CBD), Residency Program Committee (RPC), Coronary care unit (CCU), Intermediate care unit (IMCU), Tri-Council Policy Statement (TCPS2)

\section{Declarations}

Ethics and consent to participate - TCPS2 suggests that while research in Canada must undergo ethical review, program evaluation and qualitative improvements studies do not fall under the auspices of the TCPS or institutional Research Ethics Boards (TCPS2, Article 2.5). This project was described as quality improvement and after informal review with the NSHA Research Ethics Board a formal research ethics board approval was not recommended. Informed consent was obtained verbally from all participants. Given this was a quality improvement project and carried minimal risk and no likelihood of adverse events it was felt that written consent was not required.

Consent for publication - N/A 
Availability of data and materials - The datasets used and/or analysed during the current study are available from the corresponding author on reasonable request.

Competing Interests - The authors declare that they have no competing interest.

Funding - There was no funding for this project.

Author's contribution's - AM conceived the study design and was responsible for the acquisition of data. $A C, E B$ and $A M$ all contributed to data analysis, data interpretation and creation of the manuscript. AC, EB and $A M$ all approved the submitted version. AC, EB and AM all agreed both to be personally accountable for the author's own contributions and to ensure that questions related to the accuracy or integrity of any part of the work.

\section{Acknowledgements - N/A}

Author's information - Andrew James Caddell, Edwin Moses Bamwoya and Andrew Donald Moeller are adult cardiologists. They all trained as cardiology residents at Dalhousie University.

\section{References}

1. Best, L.R., Sengupta, A, Murphy, R.L.M., de Metz, C., Trotter, T., Loewen, S.K., Ingledew, P.A., and Sargeant, J. (2019). Transition to practice in radiation oncology: Mind the gap. Radiother Oncol. Sep;138:126-131.

2. Frank, J.R., Snell, L., ten Cate, O.T., Holmboe, E.S., Carraccio, C., Swing, S.R., Harris, P., Glasgow, N.J., Campbell, C., Dath, D., Harden, R.M., lobst, W., Long, D.M., Mungroo, R., Richardson, D.L., Sherbino, J., Silver, I., Taber, S., Talbot and M., Harris, K.A. (2010). Competency-based medical education: theory to practice. Medical Teacher. 32 (8): 638-45.

3. Mann, S., Truelove, A. H., Beesley, T., Howden, S., and Egan, R. (2020). Resident perceptions of Competency-Based Medical Education. Can Med Educ J. Sep; 11(5): e31-e43.

4. Sanaee, L., Nayer, M., and Takahashi, S.G. (2020). Practical solutions for implementation of Transition to Practice curricula in a competency-based medical education model. Can Med Educ J. Aug 6;11(4):e39-e50.

5. Witherspoon, L., Jalali, S., and Roberts, M.T. (2019). Resident-run urology clinics: A tool for use in competency-based medical education for teaching and assessing transition-to-practice skills. Can Urol Assoc J. Sep; 13(9): E279-E284.

\section{Supplementary}

Appendix 1 is not available with this version

\section{Figures}




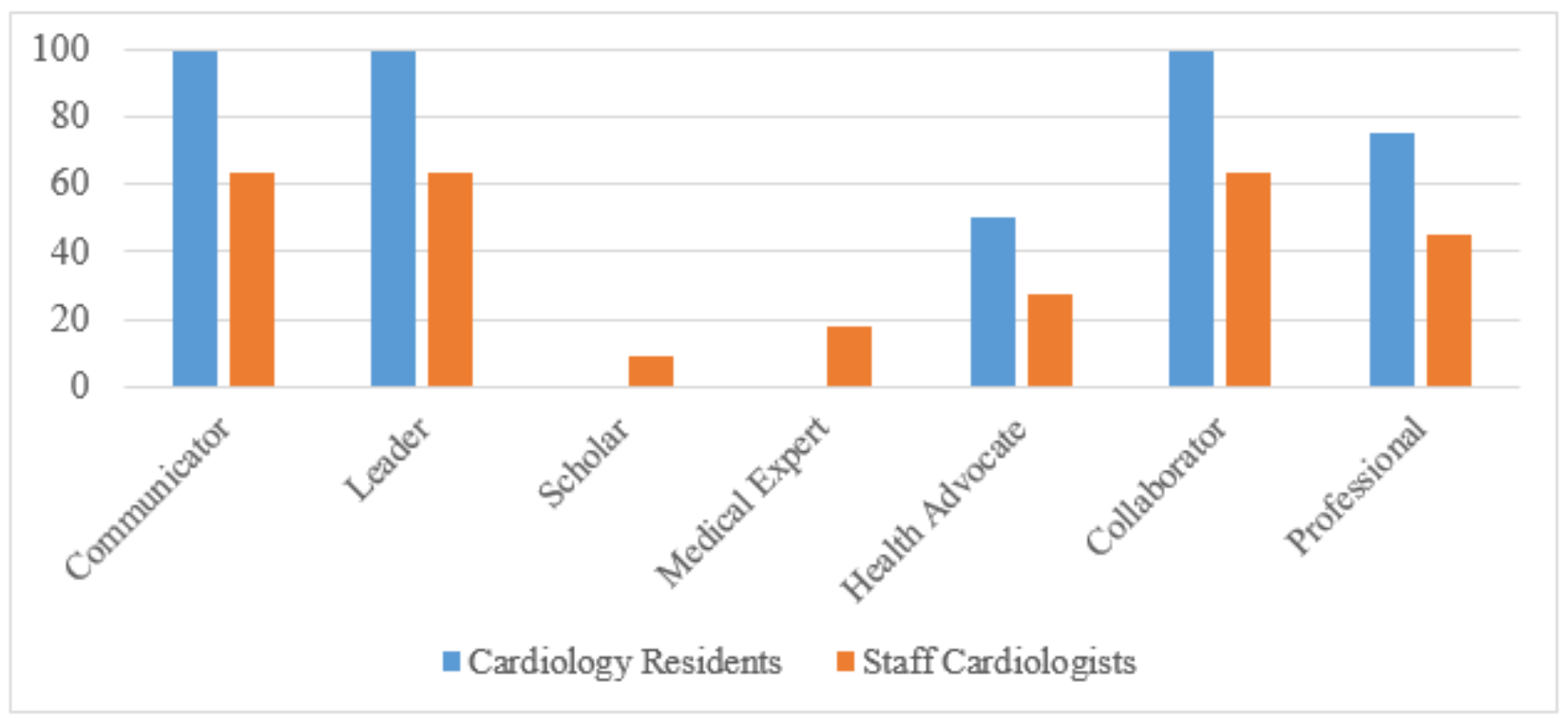

\section{Figure 1}

CanMeds roles that the Acting Triage Cardiologist role enhanced, as per both cardiology residents and staff cardiologists. The y-axis represents percentage of participants who responded affirmatively. 